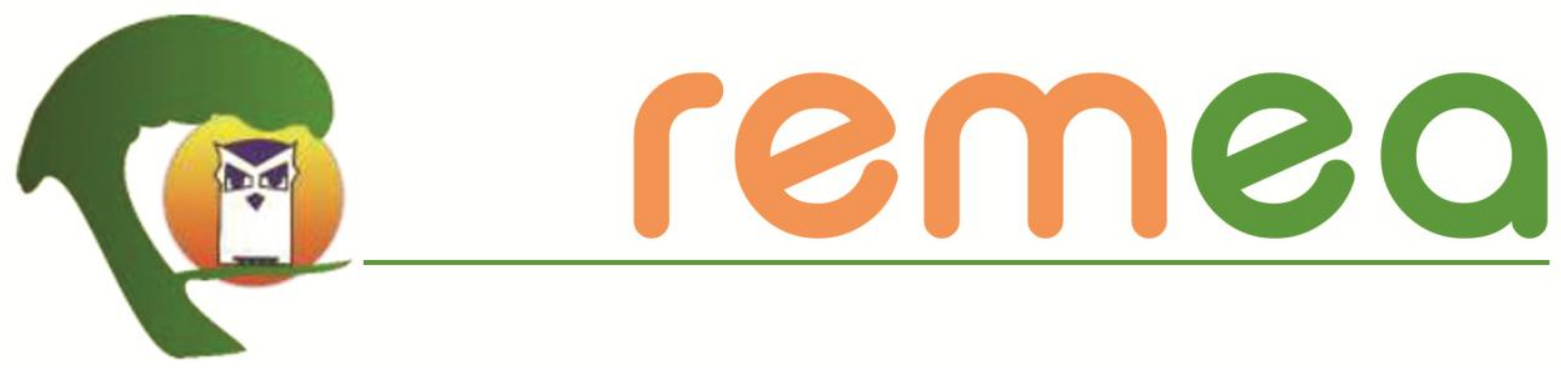

\title{
Cartografando uma Educação Ambiental Menor
}

\author{
Adalberto Ferdnando Inocêncio ${ }^{1}$ \\ Universidade Estadual de Maringá \\ ORCID: https://orcid.org/0000-0002-2659-3073 \\ Moisés Alves Oliveira² \\ Universidade Estadual de Londrina \\ ORCID: https://orcid.org/0000-0003-0102-9385
}

Resumo: O objetivo assumido nesta investigação foi o de colocar em evidência quais tecnologias/técnicas estão em jogo na experimentação de liberdades. Neste recorte, a escrita de si é enfatizada como tecnologia de si. Com base na materialidade discursiva presente nos escritos jornalísticos de Rodrigo Barchi, buscou-se cartografar uma educação ambiental menor, caracterizada pela proximidade com a micropolítica e a microfísica. Tal potência minoritária se constitui por narrativas não assimilacionistas que escapam de ecologias policialescas e normativas incitadas pela ecogovernamentalidade.

Palavras-chave: educação menor; tecnologias de si; micropolítica.

\section{Mapeo de la educación ambiental menor}

Resumen: El objetivo asumido en esta investigación fue resaltar qué tecnologías / técnicas están en juego en la experimentación de libertades. En esta sección, la escritura del yo se enfatiza como la tecnología del yo. A partir de la materialidad discursiva presente en los escritos periodísticos de Rodrigo Barchi, buscamos mapear una educación ambiental más pequeña, caracterizada por su proximidad a la micropolítica y la microfísica. Tal poder minoritario está constituido por narrativas no asimilacionistas que escapan a las ecologías policiales y normativas incitadas por la ecogobierno.

Palabras-clave: educación menor; autotecnologías; micropolítica.

\section{Cartographing minor environmental education}

Abstract: The objective assumed in this investigation was to highlight which technologies/techniques are at stake in the experimentation of freedoms. In this section, the writing of the self is emphasized as the technology of the self. Based on the discursive materiality present in Rodrigo Barchi's journalistic writings, we

\footnotetext{
${ }^{1}$ Doutor em Ensino de Ciências pela Universidade Estadual de Londrina (UEL). Professor colaborador na Universidade Estadual de Maringá (UEM). E-mail: afinocencio88@gmail.com.

2 Professor associado ao Programa de Pós-graduação em Ensino de Ciências e Educação Matemática da Universidade Estadual de Londrina (UEL). E-mail: moises@uel.br.
}

Revista Eletrônica do Mestrado em Educação Ambiental Programa de Pós-Graduação em Educação Ambiental - FURG v. 38, n. 2, p. 94-114, mai./ago. 2021. E-ISSN: 1517-1256 
sought to map a smaller environmental education, characterized by its proximity to micropolitics and microphysics. Such a minority power is constituted by non-assimilationist narratives that escape police and normative ecologies incited by ecogovernmentality.

Keywords: minor education; technologies of self; micropolitics.

\section{Introdução}

Por meio do olhar teórico embalado pelas investigações foucaultianas, visou-se cartografar modos pelos quais sujeitos constroem para si territórios outros, entendidos como formas de vida não modalizadas pela ecogovernamentalidade e ecopolítica e as relações que estas táticas ensejam por meio do que aqui se considera como macropolítica. No recorte aqui apresentado, selecionaram-se as materialidades discursivas cartografadas no âmbito educativo.

Assumiu-se como hipótese que por intermédio das tecnologias de si (conceito apresentado e discutido a seguir), é possível que certas subjetividades construam processos de recusa das formas de vida já previamente pensadas. No recorte analítico aqui apresentado, a tecnologia da escrita é posta em questão. Por meio da tecnologia de escrita de si (DUQUE-ESTRADA, 2009; FOUCAULT, 2017; RAGO, 2013), processos de subjetivação, individuais ou coletivos, criam territórios éticos, aproximando-se do que Foucault entendeu por estética da existência. Esses territórios são entendidos como movimentos de resistência aos poderes totalitários e objetivantes da ecogovernamentalidade e da ecopolítica, conceitos formulados por Malette (2011) e Passetti et al. (2019) e apresentados na seção seguinte.

No âmbito educativo, o território existencial aqui levado em questão se materializa em dois textos encontrados em páginas da internet, de autoria de Rodrigo Barchi. Ao atender três características da educação menor (GALLO, 2002; 2016), argumenta-se que a materialidade discursiva presente nesses textos contribui para a acentuação de uma educação ambiental menor, se, por esse termo, aludem-se à práticas mais livres e múltiplas no âmbito educacional, distantes dos protocolos da macropolítica dos documentos oficiais.

Como percurso metodológico adotou-se a cartografia (DELEUZE, 2013; PASSOS; KASTRUP; ESCÓSSIA, 2015). A cartografia se caracteriza por um processo de busca de relações de formas e de forças orientado pela sensibilidade do investigador. Em vez de 
protocolos rígidos e fases bem definidas, a construção do corpus analítico é experienciada neste processo. O conceito foucaultiano de estética da existência funcionou como operador na escolha da materialidade discursiva e direcionador na busca das materialidades analisadas.

\section{Da ecogovernamentalidade: a "condução de condutas" para o corpo-planeta}

A problemática da governamentalidade figurou com mais ênfase nos últimos cursos dados no Collège de France (1975-1980) e expandiu o sentido usual de governo para todo ato minucioso exercido pelo cidadão comum, individual ou coletivamente. Por governamentalidade, Foucault (2008, p. 143-144) definiu "o conjunto constituído pelas instituições, procedimentos, análises e reflexões, os cálculos e as táticas que permitem exercer essa forma bem específica [...] de poder que tem por alvo principal a população". De forma geral, trata-se de um poder que perscruta uma população em um território, e tem como finalidade última a "condução das condutas".

Há outra definição da mesma terminologia que vale à pena apresentar, dado que ela contribui para o entendimento de que o potencial minoritário se produz frente às estratégias institucionalizadas investidas pela maioridade. Deste modo, o filósofo também considera por '"governamentalidade' o encontro entre as técnicas de dominação exercidas sobre os outros e as técnicas de si" (FOUCAULT, 2014a, p. 266). Nesta conceituação, fica nítida a compreensão de que a vida não se resume à submissão das técnicas de dominação, moldando-se, simplesmente, às sedutoras táticas de poder, mas que é possível interrogar-se sobre sua própria conduta, e criar para si uma arte da existência.

Se, por um lado, a governamentalidade caracterizou-se como estratégia das sociedades liberais; nas sociedades neoliberais, em que o território a ser governado se amplia para o planeta, como um todo, consagram-se a ecopolítica (VEIGA-NETO, 2014; PASSETTI ET AL., 2019) e a ecogovernamentalidade ou, ainda, governamentalidade verde (MALETTE, 2011). Tais táticas atualizam as formas de funcionamento da biopolítica, de modo que ampliam o domínio da população para o domínio planetário (VEIGA, NETO, 2014, p. 40). 
Tais domínios ganham condição de existência e discursividade a partir da segunda metade do século passado, com a publicação do Relatório do Clube de Roma, em 1968, e a marcha das Conferências Internacionais que pautaram a questão ambiental sob o comando da ONU e a participação de inúmeros chefes de Estados. Num progressivo processo de construção de dados, documentos e relatórios, movidos por essas instâncias referidas anteriormente, "[...] as esperanças de criar uma vida melhor para toda a família humana têm sido amplamente frustradas" (PASSETTI ET AL., 2019, p. 159), uma vez que se percebeu que não houve enfrentamento efetivo à fome, às doenças, às condições de desabrigo ou ao analfabetismo, para ficar nesses exemplos, com o passar das décadas.

Ao alegar uma derrota iminente, os afetos tristes incitados por uma ecologia policialesca, ou pelo que aqui se concebe como uma Educação Ambiental Maior, “[...] aponta o 'cada um de nós', distribuindo, assim, a responsabilidade e a culpa por uma vida que fracassa, pelo pior dos mundos" (GODOY, 2007, p. 102).

Feitas tais considerações, ressalta-se que a crítica aqui estabelecida não está assentada, necessariamente, nas políticas internacionais e nacionais, haja vista que essa conquista institucionalizada representou a visibilidade dos movimentos ambientalistas e seu reconhecimento pela esfera estatal. Do ponto de vista dos autores adotados, a configuração estatal (ou de mercado), e o amplo repertório que dela devem, são formas cristalizadas de táticas micropolíticas que estão em vigor e atuam capilarmente numa dada sociedade. O que parece estar em jogo é uma busca ansiosa de diversos setores por palavras de ordem, como se apenas por meio delas fosse possível responder à problemática ambiental acionando um clamor necessário pela adoção de formas de vida fabricadas e inclinadas à sua mitigação. Por "palavras de ordem", alude-se ao sentido deleuzo-guattariano de um fenômeno de linguagem capaz de conferir ao enunciado uma força de obrigação que aprisiona a realidade em um sentido dado (DELEUZE; GUATTARI, 2011). Como se a única resposta possível aos problemas ambientais se caracterizasse pela construção de normas, leis e conselhos, deixando, em segundo plano a experimentação das subjetividades.

$\mathrm{Na}$ sequência, apresentam-se alguns nódulos do diagrama ensejado pela ecogovernamentalidade, dando ênfase aos centralizados nas políticas educativas. 


\section{Em face à ecogovernamentalidade, a Educação Ambiental Maior}

Apresentado o conceito de ecogovernamentalidade, importa destacar agora de que maneira os setores educativos acabam por colaborar com as estratégias vigentes de dominação e objetivação dos sujeitos, na medida em que são capturados pelas tecnologias de Estado. Por tecnologias de Estado, alude-se a uma capilarização de práticas de objetivação e totalização de saberes-poderes que visam ao maior alcance possível do corpo populacional.

No âmbito educativo a ecopolítica e a ecogovernamentalidade, cujas preocupações se voltam à proteção de um ambiente transnacional, convocam a população para o cuidado do corpo-planeta, estimulando a adoção dos princípios do desenvolvimento sustentável e da cultura da paz, fundindo os princípios de prescrição e precaução. Tais táticas orientam-se pelas prescrições neoliberais do capital humano, aludindo, portanto, a um empreendedorismo individual como empreendedorismo de si, o que convoca o corpo de todos a participar de um tipo de governo das inteligências orientado à monitoração e a segurança do ambiente internacional (PASSETTI ET AL., 2019).

Deste modo, adequar-se às exigências da ecopolítica não deixa de ser um processo de docilização dos corpos individuais e coletivos, sendo que uma das modalidades pelas quais essa relação pode ser notada é a da interface educação-meio ambiente, como já reconheceu Godoy:

Educar para o meio ambiente é antes adequar o corpo à Terra e adequar é restaurar equilíbrios perdidos ou conquistar equilíbrios futuros. É a saúde perfeita do corpo individual e do corpo planetário constituindo-se, concomitantemente, na promessa de reparação de danos e na prevenção de riscos. Educar para o meio ambiente apresenta-se como o cumprimento de prescrições que reduzem os corpos e as relações à conservação (GODOY, 2007, p. 124-125).

Há similaridades que se alinham na preocupação traduzida neste trecho pela autora do corpo individual com a anatomo-política em Foucault, bem como o que ela concebe por corpo planetário com a ecopolítica. A diferença, mobilizada pela ecopolítica e pela ecogovernamentalidade, é que, desta vez, “o corpo de cada um não está mais dissociado do 
planeta, é a sua extensão. É preciso cuidar da saúde do planeta vivo em relação aos planetas mortos e ao universo" (PASSETTI, 2007, p. 21).

Além disso, se nas relações que se tem com o meio ambiente espera-se algo a ser ensinado por uma prática educativa, que mais se parece com um cumprimento de prescrições - tutelando-se o que se deve ou não fazer -, a relação com a noção de norma também se faz presente nesses entrelaçamentos. Deste modo, "O problema não está nas ações que as práticas pedagógicas de EA nos ensinam: fechar a torneira, separar o lixo ou diminuir o tempo no banho", mas em pensar que "Nossos modos de vida assumem essas práticas por uma questão política, de implicações éticas no cotidiano da vida e não por uma condução de rebanho, sempre homogêneo, linear e de repetição" (HENNING; SILVA, 2018, p. 158).

É no limiar entre a biopolítica e a ecopolítica que a Educação Ambiental (em maiúsculo) se instaura, no âmbito educativo, como um novo "dispositivo de poder" que encontrou, nesse momento histórico, condições de institucionalizar-se, a fim de construir uma nova "vontade de ordem: a vontade da ordem ambiental" (MALDONADO, 2001). Não se trata de quaisquer formas de se relacionar com o meio ambiente, mas da forma encontrada pelos regimes de veridicção da modernidade (HENNING; SILVA, 2018) cuja vontade de ordem é missão primeira de seu projeto. É nesse sentido que podem ser tomados os discursos da Educação Ambiental (em maiúsculo, como prática de Estado) resultantes de Conferências Internacionais e Nacionais, bem como discursos de Leis e regulamentações oficiais - como uma nova maneira de possibilitar a subjetivação dos indivíduos (MALDONADO, 2001; HENNING; SILVA, 2018).

Compõem esse diagrama a Declaração de Estocolmo, de 1972, a Declaração de Tbilisi, de 1977, a Constituição Federal de 1988, o Tratado de Educação Ambiental para Sociedades Sustentáveis, de 1992, a Lei de Diretrizes e Bases da Educação Nacional (LDB), os Parâmetros Curriculares Nacionais (PCN), a Política Nacional de Educação Ambiental (Lei 9.795/1999), para citar alguns componentes.

Essa função de subjetivação dos indivíduos tornar-se-á praticável por uma máquina de subjetivação (capaz de produzir indivíduos em série), garantida, por sua vez, por uma 
educação maior (GALLO, 2002; 2016). A educação maior é da ordem do consenso macropolítico, isto é, das relações que emanam da função-Estado, da ordem e do controle policialesco e, por isso mesmo, daquilo que se distancia dos acontecimentos singulares do mundano.

A educação maior é aquela dos planos decenais e das políticas públicas da educação, dos parâmetros e das diretrizes, aquela da constituição e da Lei de Diretrizes e Bases da Educação Nacional, pensada e produzida pelas cabeças bempensantes a serviço do poder. A educação maior é aquela instituída e que quer instituir-se, fazer-se presente, fazer acontecer. A educação maior é aquela dos grandes mapas e projetos (GALLO, 2016, p. 64).

Como advém das funções-Estado - reificada na forma dos documentos oficiais, referidos anteriormente -, a educação maior contribui para a manutenção do status quo, uma vez que está "a serviço do poder" (GALLO, 2002; 2016). No âmbito educativo institucionalizado da educação maior, como função-Estado, só podem prescindir comportamentos orientados por práticas e condutas normativas. Por repetir incessantemente a norma, a educação maior despotencializa os atos de criação e as singularidades próprias ao mundano.

Reigota (2000) faz uma análise da presença da Educação Ambiental nos PCN da Educação Brasileira - uma modalidade de educação maior elaborada e instituída durante o governo Fernando Henrique Cardoso (1995-2002) -, afirmando que ela havia se transformado em não mais do que uma mera banalidade pedagógica. Sua indignação se dá pelo fato de ter sido um modelo importado da Espanha e não ter dado a devida relevância aos pensadores nacionais, que já desenvolviam trabalhos em Educação Ambiental há quase duas décadas. Os PCN tampouco levaram em consideração o gigantismo territorial e cultural brasileiro, estabelecendo uma perspectiva única para todo o território.

Nessa progressiva banalização, "[...] a educação ambiental que se espalha sobre a nossa sociedade e que visa distribuir informações nos apresenta de forma indireta as palavras de ordem do momento através dos slogans ecologicamente corretos" (PREVE, 2010, p. 64). Nesse exercício, a Educação Ambiental ensejada pela macropolítica alude ao desastre dominante perante o mundo e, ao erigir soluções, mais parece "pavimentar" traçados previamente planejados e pensados. 
Em oposição à educação maior, Gallo $(2002 ; 2016)$ se baseia no conceito de literatura menor, criado por Deleuze e Guattari (2017) como um dispositivo para analisar as obras de Franz Kafka, com o intuito de desenvolver a noção de educação menor. Assim como a literatura menor, a educação menor assume três características: o caráter desterritorializado, a ramificação política e o valor coletivo (GALLO, 2002; 2016). Inspirandose nessas características, buscou-se cartografar uma educação ambiental menor. Menos com a intenção de substituir a educação maior e mais com a intenção de visibilizar práticas outras, a potência minoritária da educação é uma reivindicação de singularidades que pedem passagem, a fim de uma experimentação do mundo que não seja pelas vias das palavras de ordem.

No contexto da segunda década do terceiro milênio, é pertinente a provocação de Henning (2012, p. 250) de que talvez seja necessário pensarmos em "[...] pequenas ações diárias que nos provoquem a olhar para o mundo de uma forma não aterrorizante, como muitos discursos se apresentam para nós, mas como possibilidades de compormos um pensamento minoritário para a educação ambiental".

\section{O método da cartografia e a construção do corpus analítico}

Em vez de a prioris rígidos e pré-definidos, o método cartográfico opta por um instrumental que se assemelha ao que Foucault falara uma vez sobre sua obra funcionar como uma caixa de ferramentas. Acompanhar um processo está mais próximo ao movimento arqueogenealógico que escava os ditos e os saberes e os situa na posição histórica de sua condição de existência.

Uma entrada importante é a de que no método cartográfico, há "o primado do caminhar que traça, no percurso, suas metas" (PASSOS; BARROS, 2015, p. 17). Por esta razão, em vez de um metá-hódos (metá - reflexão, raciocínio, verdade; hódos - caminho, direção), prefere-se falar em hódos-metá, de modo que objetivos são configurados durante o processo de observação. Nesse sentido, o início dessa investigação não se caracterizou pela procura de materialidades discursivas a respeito da educação menor. O conceito de ecogovernamentalidade foi adotado como operador de busca, servindo como "lentes" 
voltadas à busca de diversos arquivos, dentre eles os voltados à educação. Nesse momento de pesquisa, a atenção assume um caráter "flutuante" acerca das materialidades discursivas que poderiam compor o corpus analítico.

Como a internet é reconhecidamente a máquina de nossos tempos (DELEUZE, 1992), foram selecionados elementos discursivos, textuais e imagéticos, disponíveis em páginas diversas da internet: textos jornalísticos digitais, matérias de plataformas educacionais, páginas profissionais de artistas, dentre outras, compondo uma materialidade de possíveis elementos analíticos. Não foram fixadas de antemão categorias textuais para investigar, priorizando possíveis áreas distintas que pudessem ser encetadas pelos "tentáculos" da ecogovernamentalidade.

$\mathrm{Na}$ incursão às páginas da internet que levassem em seu título as terminologias meio ambiente, ecologia, educação ambiental etc. não foram identificadas estéticas da existência ou ruptura com as formas totalitárias de poder da ecogovernamentalidade. Dessa forma não foram essas materialidades as mantidas na análise. A exemplo, as páginas "Discutindo ecologia", "Cultura, Cidadania e Meio Ambiente" e a própria página oficial do Ministério do Meio Ambiente, todas elas ligadas à rede social Facebook. Nestas páginas, foi comum uma ênfase na divulgação científica, reportando-se notícias que dizem respeito ao problema dos canudos plásticos, do desmatamento, extinção de espécies, papel dos ambientalistas na história brasileira, divulgação de cursos, dentre outros assuntos. As notícias e reportagens, em sua maioria, são escritas em terceira pessoa, com ênfase num papel denuncista e policialesco.

Passos, Kastrup e Escóssia (2015) indicam que o funcionamento da atenção no trabalho do cartógrafo é orientado por um tipo de bússola. Na imersão por uma série de textos - enunciados, discursos e relações de força - foram selecionados aqueles que se caracterizaram como estéticas da existência construídas em um formato diferente das relações guiadas pela ecogovernamentalidade. São textualidades que se caracterizam por estéticas da existência, ou práticas de liberdade, construídas em oposição aos agenciamentos do Estado ou mercado (FOUCAULT, 2014a) e, por isso, reconhecidos em seu caráter de contraconduta e resistência, traços de um potencial minoritário. 
Foram mantidos os elementos foucaultianos analíticos das fases arqueológica e genealógica - a análise dos saberes e poderes subjacentes às suas respectivas condições históricas de existência, suas descontinuidades e estridências - buscando identificar o potencial minoritário dos ditos. Nesses elementos materiais selecionados, identificam-se processos de subjetivação de diversas formas e operando em setores diversos, como no âmbito educativo.

Na materialidade analisada neste recorte, priorizaram-se os arquivos que se referiam ao campo educativo. Importa anunciar, por fim, que a educação menor não intenciona se tornar um campo educativo hegemônico, seja na abordagem, seja como campo de pesquisa. Deste modo, é lógico afirmar que o potencial minoritário seria encontrado em textualidades de frequência e intensidades reduzidas, ou seja, em menor número e contrastando com as materialidades consagradas como tendências da Educação Ambiental brasileira, em maiúsculo (NOAL; REIGOTA; BARCELOS, 1998).

\section{O potencial minoritário da educação ambiental e as reivindicações de singularidade}

Ambos os textos selecionados para compor o recorte analítico apresentado nesta seção estão publicados na edição digital do Jornal Cruzeiro do Sul. Tratam-se dos artigos: "Educação Ambiental e Política", publicado no ano de 2014, e "A educação ambiental contra o desenvolvimento sustentável", publicado no ano de 2017. Ambos os artigos são assinados por Rodrigo Barchi'

De que modos as composições presentes nestes textos tergiversam, provocam, perturbam ou mesmo pervertem (como utiliza o autor) as táticas postas pela ecogovernamentalidade? Argumenta-se que o estilo de escrita do autor, inspirado em uma perspectiva anárquica em educação, desmonta uma noção de Educação Ambiental em maiúsculo, sendo esta a perspectiva institucionalmente territorializada como uma verdade, ou modelo ideal de ecogovernanças postas em circulação pelos aparelhos de Estado e das

3 Os textos podem ser conferidos na íntegra por meio do acesso aos links: https://nave.wordpress.com/2014/01/22/educacao-ambiental-e-politica/ e

https://www2.jornalcruzeiro.com.br/materia/773312/a-educacao-ambiental-contra-o-desenvolvimentosustentavel, respectivamente. 
entidades corporativas na atual conjuntura. Perspectiva esta que alude à definição dada por Gallo $(2002 ; 2016)$ de uma educação maior, mas que também pode ser entendida nas definições de Maldonado (2001), como uma ordem do discurso da Educação Ambiental, de Palharini (2005), numa Educação Ambiental como acontecimento ou, ainda, uma Educação Ambiental do dissenso, como teorizada por Henning e Silva (2018).

Barchi (2017) inicia um dos textos problematizando, justamente, a construção social do papel da verdade ao trazer à luz uma narrativa de Bertold Brecht, escrita nos anos 1930. Mais precisamente, enfatiza a passagem brechtiana: "as pessoas que são contrárias ao fascismo sem ser contra o capitalismo, são as mesmas que querem comer a vitela sem matar a bezerra", usando da linguagem metafórica para se referir a um conjunto de relações pelas quais as pessoas se mantêm na superficialidade de alguns problemas. Que superficialidade é essa, presente na materialidade desses ditos?

Afirma ele que as pessoas que contestam a barbárie são as mesmas incapazes de detectar as relações de poder imanentes àquela, isto é, criticam-se relações decorrentes de organização social, mas não as bases materiais, políticas e discursivas que as ensejam. É este o traço subversivo imanente à sua escrita. O autor usa desses elementos para se referir à incessante e crescente captura dos "barulhos" proporcionados pelos movimentos ecologistas internacionais, realizada tanto pelos governos nacionais quanto pelas empresas internacionais.

Trata-se de uma perversa despolitização do discurso desses movimentos que, a partir dos anos 1960, passaram a ganhar a atenção dos aparelhos midiáticos. Nesta ruptura histórica, Barchi (2017, s.p.) argumentará que, de reivindicação dos movimentos ecologistas que ganharam força após a Segunda Guerra, "a ecologia tornou-se verborragia nos discursos dos chefes de estado, dos políticos e do empresariado". Há, aí, uma discursividade que não se identificava até então.

Se a ecologia social proclamada pelos movimentos ecologistas não coadunava com os interesses empresariais ou da governança estatal, consistindo em sua crítica ferrenha, o autor argumentará que, com a criação do conceito desenvolvimento sustentável - imanente à publicação do Relatório Brundtland, em 1987 (organizado pela Comissão Mundial sobre o 
Meio Ambiente e Desenvolvimento) - "a ecologia, do dia para a noite [...], transformou-se em boa aliada da manutenção do poder e das desigualdades inerentes ao capitalismo" (BARCHI, 2017, s.p.).

É esta a ecologia que "come a vitela sem matar a bezerra". Ao adequar-se aos apelos estatais e empresariais, esse discurso esvazia-se das exigências políticas (afinal, quem será contra uma educação para o desenvolvimento sustentável ${ }^{4}$ ?) que a caracterizavam quando proclamada pelos movimentos ecologistas, que, em suas derivações no âmbito educativo, segundo o autor, buscavam se fundamentar como ferramentas de combate frente à destruição do planeta. Ao haver uma adequação, de educação ambiental - em minúsculo, caracterizada por propostas políticas provenientes dos próprios movimentos ecológicos para "educação ambiental para o desenvolvimento sustentável" (também em minúsculo, mas não menos institucionalizada), não há só alteração na força conceitual, mas uma série de efeitos gerados pela sua propagação. Essa modalidade enunciativa dilui seu papel de transformação social e não mais luta contra o capitalismo, mas se efetiva apesar dele.

Deste modo, se a institucionalização dessas práticas no âmbito educativo representa, por um lado, uma conquista política, responsabilizando a figura do Estado como agência de governo responsável pela obrigatoriedade de implementar abordagens ambientais nas esferas educativas, por outro:

[...] ao tornar uma proposta política e educacional de grande potencial de transformação que é a educação ambiental em uma lei que provavelmente perdurará cristalizada e imutável por décadas é um fato atravessado por um grave risco negativo. Ao fazer da educação ambiental um discurso da verdade e uma mera impositiva de normas e condutas, hierarquizando as posturas sociais e políticas dos indivíduos a partir do que é o ecologicamente correto ou incorreto,

\footnotetext{
4 No delineamento analítico adotado nesta pesquisa, a proposta discursiva da "educação para o desenvolvimento sustentável" também consiste em um feixe que integra a ecogovernamentalidade, uma vez que visa governar as condutas humanas. Como estabelecido na página da Organização das Nações Unidas para a Educação, a Ciência e a Cultura (UNESCO), o maior objetivo desta vertente "é estimular mudanças de atitude e comportamento nas populações, uma vez que as capacidades intelectuais, morais e culturais do homem nos impõem responsabilidades para com outros seres vivos e para com a natureza como um todo " (Disponível em: http://www.unesco.org/new/pt/brasilia/about-this-office/prizes-and-celebrations/2005-2014-the-united-

nations-decade-of-education-for-sustainable-development/). Se há o intuito de mudança de comportamento, há uma pedagogização e, se esta se direciona a um coletivo populacional, há governamentalidade como estratégia de poder.
} 
essa institucionalização pode criar centralizações de poder que não condizem com as clássicas reivindicações dos movimentos ecologistas (BARCHI, 2014, s/p).

Ao operar pelo binômio correto-incorreto, tal institucionalização no âmbito educativo incorre no risco de atualizar noções de normalização do comportamento, estando próxima às palavras de ordem da educação maior, por meio das quais as subjetividades conhecem uma verdade sem, contudo, alterar a si mesmas por procedimentos ético-estéticos. $\mathrm{Na}$ modalidade maior da educação, a subjetividade não experimenta nem troca, apenas assimila um processo de subjetivação repetitivo. Ao dizimar qualquer possibilidade de singularização, isto é, de experimentações que destoem do que está proposto na macropolítica, "precisa-se temer pelo fato de suas reivindicações tornarem-se dispositivos, ferramentas e instrumentos do exercício de um poder governamental, o qual pode acabar descambando para o exercício de um fascismo verde e/ou ecológico" (BARCHI, 2014, s/p).

É como se tratasse de um tipo de "lifting" discursivo, processado e "personificado nas propagandas de bancos, empreiteiras e até frigoríficos" (BARCHI, 2014, s/p), atendendo a organizações para as quais esse discurso de "bom mocismo" interessa, como reconhece o autor. É neste âmbito que ele estabelece o seguinte questionamento:

\footnotetext{
O ecocapitalismo que sustenta a noção de educação para o desenvolvimento sustentável consegue superar o horror narrado por Brecht, pois se antes se lamentava a morte da bezerra, hoje não se lamenta mais, pois se ela foi assassinada, pelo menos o foi a partir de "práticas humanitárias" de abate. Será que é para isso que o pseudo esverdeamento do capitalismo nos prepara, não para nos dar qualidade de vida, igualdade e justiça, mas para nos abater de modo menos cruel? (BARCHI, 2017, s/p.).
}

Trata-se de uma pergunta em tom cínico, pois o autor sabe que a resposta a esta questão é afirmativa. Considera-se que a escrita de Barchi desmonta uma dupla construção histórica: a derivação institucionalizada (e mais específica) como "educação ambiental para o desenvolvimento sustentável"; mas, também, a própria educação ambiental (mais genérica), que não esteve "desde sempre aí".

\footnotetext{
${ }^{5}$ É preciso resgatar que estas inclinações no âmbito educativo se caracterizam como discursos recentes na história. Refere-se ao acontecimento da Assembleia das Nações Unidas, que proclamou o período de 2005 a 2014, como a "Década Internacional da Educação para o Desenvolvimento Sustentável" (DEDS). Essa proposta fora aprovada em sua 57ạ sessão, em dezembro de 2002.
} 
Nesse desmontar, há uma recusa da ecogovernamentalidade como ato de revolta e resistência, atendendo à primeira característica da educação menor, a desterritorialização. Ao reconhecer que a educação, em seu caráter majoritário, pode se configurar num "fascismo verde", ocorre a subversão de uma língua maior. Ao se referir, ainda, a um pseudo esverdeamento, endereça-se à educação ambiental para o desenvolvimento sustentável um veículo de sua própria desagregação, uma vez que seu potencial político é reconhecido como esvaziado.

Não se trata, então, de uma crítica ao que seriam as tendências já consolidadas na realidade brasileira, como se reconhecem pela Educação Ambiental conservadora, Crítica ou Emancipatória, para citar as vertentes bastante mapeadas nos cenários brasileiros (NOAL; REIGOTA; BARCELOS, 1998), mas de um campo de práticas discursivas de dimensões internacionais que incidem nas instâncias educativas, reverberando novos mecanismos de regulação social, quais sejam um rol de novos saberes - como a gestão ambiental e a economia sustentável - que reconhecem ser possível continuar um modo de reger a vida capitalística, mas, desta vez, sob a retórica sustentável, isto é, já "sacrificadas por práticas humanitárias de abate", na metáfora do autor. Ao invés de buscar as grandes políticas que nortearão os atos cotidianos, empenhando-se nos atos cotidianos propriamente ditos (GALLO, 2002), Barchi acaba por atender à segunda característica da educação menor, sua ramificação política.

Na sequência, resgatam-se as considerações de Deleuze e Guattari (2017) de que, ao falarem de autoria, implicam uma multiplicidade de vozes em que autores entram em agenciamentos coletivos de enunciação. Trata-se da terceira caracterização da educação menor, seu valor coletivo. Nesta perspectiva, considera-se que tanto o que este autor escreveu em outro momento, quanto os registros produzidos por outras autorias, estabelecem intertextualidade com a produção aqui levada em conta.

Há ressonâncias na escrita de Barchi que encontram ecos em uma das produções de Luciana Palharini. Essa autora também explora a singularidade da Educação Ambiental como um acontecimento, e utiliza terminologia na acepção foucaultiana para explorar sua potência na produção de verdades de um tempo. Pensar a Educação Ambiental como um 
acontecimento histórico do final do século XX é captá-la numa singularidade, unicidade e agudez. Dito de outro modo, "significa pensar sua produção discursiva não como conhecimento que representa um acúmulo e uma evolução do conhecimento, mas como verdades que são também históricas e cuja formação se dá por uma rede discursiva" (PALHARINI, 2005, p. 1-2).

No mesmo direcionamento ético, Maldonado (2001, p. 11) já alertara que, para entender os regimes de verdade da Educação Ambiental, se faz necessário "desnaturalizar a emergência desses discursos, concebendo-os como acontecimentos históricos"; além disso, acredita que, "desconstruindo o discurso sobre a necessidade da Educação Ambiental, é possível perceber as relações de poder que o possibilitaram".

Por fim, Henning e Silva (2018, p. 151) encorajam "estranhar a relação quase direta entre EA e a solução para os problemas ambientais", e argumentam que "[...] rastros históricos imbricam, quase automaticamente, Educação, Educação Ambiental e valores modernos". Ao fabricarem o que as autoras chamam de "verdades educacionais e modos clichês de vida verde", esses arranjos educacionais "[...] estão tramados com as estratégias de governo das condutas e capturas dos sujeitos, dirigindo suas consciências e orientando-os para ações ecologicamente corretas, subjetivando indivíduos e capturando modos de vida" (HENNING, SILVA, 2018, p. 153). Educações Ambientais outras, possíveis, que rompem com a proposta de tudo solucionar, seria, para as autoras, uma Educação Ambiental do dissenso.

Atendendo às três características da potência minoritária da educação, desarma-se uma Educação Ambiental lida como modalidade de saber-poder orientadora de práticas voltadas a um mundo melhor. Ao lê-la em sua relação com "as verdades que ela cria", é possível materializar uma série de relações de poder, como: "[...] o que implica essa autorização de uns em detrimento de outros para falar sobre educação ambiental"; "que efeitos são gerados por esse mecanismo disciplinar, que disciplina, quem e o que deve ser dito acerca desse fazer educativo" e "pensar sobre o lugar da verdade, onde ela reside, o que torna possível o acesso a ela e a quem interessa acessá-la" (PALHARINI, 2005, p. 1).

Desarmar os potenciais efeitos de uma função-Estado não é pouca coisa, uma vez que, ao restituir ao discurso seu caráter de acontecimento, evidencia-se "tudo o que possa 
haver aí de violento, de descontínuo, de combativo, de desordem, também, e de perigoso, desse grande zumbido incessante e desordenado do discurso" (FOUCAULT, 2012, p. 48).

Barchi (2017) esboça um movimento de critica a esse estatuto já bastante delineado da "educação ambiental para o desenvolvimento sustentável" em termos do que se espera das práticas e condutas humanas, que parecem não favorecer espaços de liberdade. Ao não ceder a uma "educação ambiental para o desenvolvimento sustentável", cria-se um nódulo de reivindicação abstrata de singularidades que não podem estar presentes nas narrativas institucionalizadas e maiores. Justamente por essas questões, o autor não faz a opção por uma substituição: "vejam vocês, agora Ihes apresento outra perspectiva, mais "verdadeira" de pensamento. Sigam-na" ${ }^{6 \prime}$.

Operando nessa linha, a "educação menor", proposta por Gallo (2016, p. 62), visa "investir num processo educativo comprometido com a singularização, comprometida com valores libertários". É o que problematiza Barchi $(2014,2017)$ ao chamar a atenção de uma educação que mantém em vigor as "práticas de abate" humanizadas de um capitalismo há séculos em vigor. Do mesmo modo que uma "literatura menor visa subverter a língua, fazer com que ela seja o veículo de desagregação dela própria" (DELEUZE; GUATTARI, 2017, p. 25), a "educação menor é um ato de revolta e de resistência. Revolta contra os fluxos instituídos, resistência às políticas impostas [...] Uma educação menor é um ato de singularização e de militância" (GALLO, 2016, p. 64-65).

Deste modo, a escrita de Barchi (2017) ressoa o que já parecemos saber: de que a atuação de máquinas que operam no funcionamento de estruturas centralistas e universalistas - que se impõe institucionalmente por um movimento "de cima para baixo" repete a ilusão das escolhas nas lutas democráticas, pois essas são produzidas na macropolítica dos gabinetes e documentos oficiais, incapazes de dar conta das ações cotidianas (GALLO, 2016).

Em vez de legislar, perspectiva que não apenas enxerga, mas constrói um mundo a partir de leis, planos e diretrizes para fazê-lo acontecer, a "educação menor" está mais

\footnotetext{
6 “Não queremos definir um novo modo de fazer EA. Mas nos colocamos no jogo da luta para guerrear com a EA [...] que aciona em nós apenas a expiação da culpa e a necessidade de revermos nossos atos perante a natureza" (HENNING; SILVA, 2018, p. 158).
} 
interessada nas microrrelações cotidianas, que constroem um mundo dentro do mundo (GALLO, 2016). O afã da potência menor da educação (e da escrita, como tecnologia) sempre implica em recusas. Neste caso, serve a consideração de Negri e Guattari $(2017$, p. 88) sobre o tempo presente caracterizado pelas experimentações: “[...] não possuímos nenhum modelo substituto de organização, mas ao menos sabemos o que não queremos mais".

Adequar-se, simplesmente, ao que apregoam as demandas decorrentes de discursos institucionalizados pode acarretar processos que regem a força produtiva do social nos moldes que interessam a certas instâncias; processos estes que se operacionalizam pela tripartição: formação, execução e administração da direção política. Tal separação pode ser amenizada quando os sujeitos são capazes da criação de suas próprias estratégias de luta, que mais se assemelham a "um movimento multicéfalo e uma organização proliferante que não propõe 'palavras de ordem', mas sim 'proposições diagramáticas'” (NEGRI; GUATTARI, 2017, p. XVIII).

Barchi tensiona um escape aos agenciamentos de controle que se expressam pela sobrecodificação burocratizante de instâncias que geram zonas de consenso, como são, neste caso, a ONU, a UNESCO ou mesmo as tendências já bastante mapeadas e, por esse mesmo motivo, territorializadas da Educação Ambiental brasileira. Seu texto não deixa de representar novos agenciamentos que buscam neutralizar aquilo que não diz respeito aos interesses singulares, movimento que, aliás, sempre existirá, uma vez que "quanto mais se esforça na direção de tentar delimitar-se, criar suas especificidades, seus princípios, mais diferenças proliferam incessantemente" (PALHARINI, 2005, p. 3).

Em vez da territorialidade forçada, característica da "ordem do discurso da Educação Ambiental" e da educação maior, a escrita de Barchi inclina-se para a subversão dessa realidade sem oferecer outra no lugar. O autor prefere o múltiplo, os encontros possíveis com o mundano e as fugas, impraticáveis no plano da macropolítica educacional. Seus traços subjetivos de resistência também reconhecem que, "do ponto de vista molecular, cada tentativa de unificação ideológica é uma operação absurda e reacionária" (NEGRI; GUATTARI, 2017, p. 91 grifos dos autores). 
Segundo Passos e Barros, "Quando narramos um caso, podemos fazer uma experiência narrativa minoritária, pondo-nos em uma posição de estrangereidade ao que habitualmente é dito" (PASSOS; BARROS, 2015, p. 164). Por meio da escrita de si, desmontase a suposta verdade aparentemente inabalável da crise ambiental e dos modos de vida estagnados e obedientes enredados às forças de sua enunciação. "Colocamo-nos, então, em posição de estranhamento, de interrogação ao que certa narrativa aceitaria como natural e regra, forçando a um deslocamento do dito na busca das condições de sua produção" (PASSOS; BARROS, 2015, p. 164).

Finaliza-se esse eixo analítico com as palavras de Guimarães (2009, p. 2), que pondera, sobre exercícios similares a esses trazidos para a análise, que "essa invenção/reinvenção de narrativas favorece nosso trabalho de colocar modos recorrentes e naturalizados de ver um ambiente em suspensão, promovendo fugas aos clichês instalados". Ao colocar as relações de saber-poder no caráter de acontecimento, não se deseja "preservar", manter intacto um ambiente ou uma cultura, mas propiciar hibridações que potencializem expressões atualizadas de vidas nos ambientes.

\section{CONSIDERAÇÕES FINAIS}

Desde a institucionalização da Educação Ambiental sob o crivo da macropolítica educacional, esta derivação do âmbito educativo tem assumido caráter de discurso eleito. Sob a leitura da ecogovernamentalidade como técnica de poder vigente nas sociedades neoliberais, problematiza-se o caráter institucionalizado das práticas educativas que, na modalidade de educação maior, reproduz relações sob interesses do capital globalizado.

Numa investigação que levou em conta o conceito foucaultiano de tecnologia de si, percebeu-se que não apenas por meio das palavras de ordem se experiencia a crise ambiental no tempo presente. A escrita de si foi identificada como prática de contraconduta e resistência na medida em que alude a outros modos de viver no planeta. Em vez da macropolítica que alude a uma Educação Ambiental como função-Estado, a educação ambiental menor, desterritorializada, em ramificação política e de valor coletivo, encontrase mais próxima dos processos microfísicos e micropolíticos do mundano. 


\section{Referências}

BARROS, Laura Pozzana de; KASTRUP, Virgínia. Cartografar é acompanhar processos. In: PASSOS, Eduardo; KASTRUP, Virgínia; ESCÓSSIA, Liliana da. Pistas do método da cartografia: Pesquisa-intervenção e produção de subjetividade. Porto Alegre: Sulina, 2015.

DELEUZE, Gilles. Conversações. São Paulo: ed. 34, 1992.

DELEUZE, Gilles. Foucault. São Paulo: Brasiliense, 2013.

DELEUZE, Gilles; GUATTARI, Félix. Postulados da linguística. In. Mil platôs: capitalismo e esquizofrenia 2, vol. 2. 2. ed. São Paulo: Editora 34, 2011.

DELEUZE, Gilles. Kafka: por uma literatura menor. Belo Horizonte: Autêntica Editora, 2017.

DUQUE-ESTRADA, Elizabeth Muylaert. Devires autobiográficos: a atualidade da escrita de si. Rio de Janeiro: NAU/Editora PUC-Rio, 2009.

FOUCAULT, Michel. Segurança, Território, População. Martins Fontes: São Paulo, 2008.

FOUCAULT, Michel. A ordem do discurso. 22. ed. São Paulo: Edições Loyola, 2012.

FOUCAULT, Michel. As Técnicas de Si. In: FOUCAULT, Michel. Ditos e escritos, v. IX: genealogia da ética, subjetividade e sexualidade. (Organizado por Manoel Barros da Motta). Rio de Janeiro: Forense Universitária, 2014a.

FOUCAULT, Michel. História da sexualidade 2: O uso dos prazeres. São Paulo: Paz e Terra, 2014b.

FOUCAULT, Michel. A escrita de si. In: FOUCAULT, Michel. Ditos e escritos, v. V: ética, sexualidade, política. 3. ed. (Organizado por Manoel Barros da Motta). Rio de Janeiro: Forense Universitária, 2017.

GALLO, Sílvio. Em torno de uma educação menor. Revista Educação \& Realidade. ed. 27, v. 2. jul/dez. 2002. (p. 169-178).

GALLO, Sílvio. Deleuze \& a Educação. 3. ed. Belo Horizonte: Autêntica Editora, 2016.

GODOY, Ana. Conservar docilidades ou experimentar intensidades. In: PREVE, Ana Maria; CORRÊA, Guilherme (Orgs.). Ambientes da ecologia: perspectivas em política e educação. Santa Maria: Editora da UFSM, 2007.

GODOY, Ana. A menor das ecologias. São Paulo: Editora da USP, 2008. 
GUIMARÃES, Leandro Belinaso. A invenção de dispositivos pedagógicos indagativos sobre o ambiente. In: XII Congresso da Associação Internacional para Pesquisa Intercultural (ARIC), 2009, Florianópolis. Anais... Florianópolis: ARIC, 2009, v. 1. p. 01-13.

HENNING, Paula Corrêa. Provocações para este tempo... a educação ambiental e os atravessamentos midiáticos. In: PREVE, Ana Maria Hoepers; GUIMARÃES, Leandro Belinaso; BARCELOS, Valdo; LOCATELLI, Júlia Schateck (Orgs.). Ecologias inventivas: conversas sobre educação. Santa Catarina: Edunisc, 2012.

HENNING, Paula Corrêa; SILVA, Gisele Ruiz. Rastros da Educação Ambiental. O dissenso como potência criadora. In: HENNING, Paula Corrêa; MUTZ, Andresa Silva da Costa; VIEIRA, Virgínia Tavares. (Orgs.). Educações Ambientais possíveis: ecos de Michel Foucault para pensar o presente. Curitiba: Appris, 2018.

KASTRUP, Virgínia. O funcionamento da atenção no trabalho do cartógrafo. In. PASSOS, Eduardo; KASTRUP, Virgínia; ESCÓSSIA, Liliana da. Pistas do método da cartografia: Pesquisa-intervenção e produção de subjetividade. Porto Alegre: Sulina, 2015.

MALDONADO, Maritza Maciel Castrillon. A ordem do discurso da educação ambiental. Porto Alegre: UFRGS, 2001. Dissertação (mestrado) - Universidade Federal do Rio Grande do Sul. Faculdade de Educação. Programa de Pós-Graduação em Educação.

MALETTE, Sébastien. Foucault para o próximo século: ecogovernamentalidade. Ecopolítica. v. 1.2011 (p. 4-25). Disponível em: < https://revistas.pucsp.br/index.php/ecopolitica/article/view/7654>. Acesso em: 26/11/2016. NEGRI, Antônio; GUATTARI, Félix. As verdades nômades: por novos espaços de liberdade. São Paulo: Autonomia Literária e Editora Politeia, 2017.

NOAL, Fernando Oliveira; REIGOTA, Marcos; BARCELOS, Valdo Hermes de Lima (Orgs.). Tendências da Educação Ambiental brasileira. Santa Cruz do Sul: EDUNISC, 1998.

PALHARINI, Luciana. A Educação Ambiental enquanto acontecimento. In: 28a Reunião Anual da Associação Nacional de Pesquisa e Pós-Graduação em Educação (ANPEd), 2005, Caxambu/ MG. Anais da 28a Reunião Anual da Associação Nacional de Pesquisa e PósGraduação em Educação (ANPEd). Rio de Janeiro/ RJ: ANPEd, 2005. Disponível em: http://www.anped.org.br/sites/default/files/gt22-3132-int.pdf. Acesso em 03/05/2018.

PASSETTI, Edson. Ecopolítica e controle por elites. In: PREVE, Ana Maria; CORRÊA, Guilherme. (Orgs). Ambientes da ecologia: perspectivas em política e educação. Santa Maria: Editora da UFSM, 2007.

PASSETTI, Edson; AUGUSTO, Acácio; CARNEIRO, Beatriz; OLIVEIRA, Salete; RODRIGUES, Thiago. Ecopolítica. Hedra: São Paulo, 2019. 
PASSOS, Eduardo; KASTRUP, Virgínia; ESCÓSSIA, Liliana da. Pistas do método da cartografia: Pesquisa-intervenção e produção de subjetividade. Porto Alegre: Sulina, 2015.

PASSOS, Eduardo; BARROS, Regina Benevides. Por uma política da narratividade. In: PASSOS, Eduardo; KASTRUP, Virgínia; ESCÓSSIA, Liliana da. Pistas do método da cartografia: Pesquisa-intervenção e produção de subjetividade. Porto Alegre: Sulina, 2015.

PREVE, Ana Maria Hoepers. Onde sonham as formigas verdes: sonho, silêncio, vazio. In: GUIMARÃES, Leandro Belinaso; KRELLING, Aline; BARCELOS, Valdo (Orgs.). Tecendo Educação Ambiental na arena cultural. Petrópolis: DP et Alii Editora Ltda., 2010.

RAGO, Margareth. A aventura de contar-se: feminismos, escrita de si e invenções da subjetividade. Campinas: Editora da Unicamp, 2013.

REIGOTA, Marcos. La transversalidad en Brasil: uma banalización neoconservadora de uma propuesta pedagógica radical. Tópicos en Educación Ambiental, México, v. 2, n. 6, p. 19-26, 2000. Disponível em: http://www.bvsde.paho.org/bvsacd/cd37/top26p19.pdf. Acesso em: 22/07/2017.

SIQUEIRA, Leandro. Derivas siderais, ecopolítica e governamentalidade planetária.

Ecopolítica. São Paulo. v. 15. 2016 (p. 2-36). Disponível em:

https://revistas.pucsp.br/ecopolitica/article/view/28360/20571. Acesso em: 22/08/2017.

VEIGA-NETO, Alfredo. Ecopolítica: um novo horizonte para a biopolítica. Revista Eletrônica do Mestrado de Educação Ambiental. V. Especial, dez/2014. Disponível em: https://periodicos.furg.br/remea/article/view/4860/3045. Acesso em: 22/08/2018.

FONTES

BARCHI, Rodrigo. Educação Ambiental e Política. Jornal Cruzeiro do Sul, 2014. Disponível em: https://nave.wordpress.com/2014/01/22/educacao-ambiental-e-politica/. Acesso em: 22/07/2017.

BARCHI, Rodrigo. A educação ambiental contra o desenvolvimento sustentável. Jornal Cruzeiro do Sul, 2017. Disponível em:

https://www2.jornalcruzeiro.com.br/materia/773312/a-educacao-ambiental-contra-odesenvolvimento-sustentavel. Acesso em: 22/07/2017. 